\title{
Celerinatantimonas diazotrophica gen. nov., sp. nov., a nitrogen-fixing bacterium representing a new family in the Gammaproteobacteria, Celerinatantimonadaceae fam. nov.
}

\author{
Melissa J. Cramer,† Nicole Haghshenas,‡ Christopher E. Bagwell,§ \\ George Y. Matsui and Charles R. Lovell \\ Department of Biological Sciences, University of South Carolina, Columbia, SC 29208, USA
}

Correspondence

Charles R. Lovell

lovell@biol.sc.edu

Five strains representing a novel family within the Gammaproteobacteria were isolated from the estuarine grasses Spartina alterniflora and Juncus roemerianus. All strains were facultatively anaerobic, Gram-negative, short, motile, polar monotrichous rods that were mesophilic, oxidasenegative, catalase-positive, had DNA G +C contents of $41.5-44.4 \mathrm{~mol} \%$ and required seawater salts or $\mathrm{NaCl}$. Growth was observed at $\mathrm{pH}$ 3.5-8.0. Polar lipids diphosphatidylglycerol, phosphatidylglycerol, phosphatidylethanolamine, phosphatidylmonomethylethanolamine, aminophospholipid, phospholipids and unidentified aminolipids were found in the representative strain S-G2-2 ${ }^{\top}$. The major menaquinone and ubiquinone were MK-8 (100\%) and Q-8 (93\%), respectively. Predominant fatty acids present were $\mathrm{C}_{12: 0}$ aldehyde and/or unknown fatty acid 10.9525 (MIDI designation) and/or iso- $\mathrm{C}_{16: 1} \mathrm{l} / \mathrm{C}_{14: 0} 3-\mathrm{OH}, \mathrm{C}_{16: 1} \omega 7 c / \mathrm{C}_{16: 1} \omega 6 c, \mathrm{C}_{16: 0}, \mathrm{C}_{17: 0}$ cyclo and $\mathrm{C}_{18: 1} \omega 7 \mathrm{c}$ and/or $\mathrm{C}_{18: 1} \omega 6 \mathrm{c}$. The nearly full-length $16 \mathrm{~S}$ rRNA gene sequences of the strains were very similar (99-100\% similarity), and the strains were identified as members of the same species by DNA-DNA relatedness measurements. 16S rRNA gene sequence analysis revealed that the strains formed a monophyletic lineage within the order Alteromonadales. All five strains fixed $\mathrm{N}_{2}$. Analysis of partial nifH gene sequences also revealed a monophyletic lineage within the Gammaproteobacteria, and the sequences were dissimilar to those of any previously described diazotroph. Differences between the novel strains and other members of the Alteromonadales include the inability to produce cytochrome oxidase. The novel strains were metabolically versatile. On the basis of the information described above, the new genus and species Celerinatantimonas diazotrophica gen. nov., sp. nov. are proposed to accommodate the five strains within a new family, Celerinatantimonadaceae fam. nov. The type strain of Celerinatantimonas diazotrophica is S-G2-2 ${ }^{\top}\left(=\right.$ ATCC BAA $-1368^{\top}=$ DSM $\left.18577^{\top}\right)$.

†Present address: R\&D ST\&O OC Laboratory, Dow Agrosciences, Indianapolis, IN 46268, USA.

$\ddagger$ Present address: Medical University of South Carolina, Charleston, SC, 29425, USA.

§Present address: Environmental Sciences \& Biotechnology, Savannah River National Laboratory, SRNL, Aiken, SC, USA.

Abbreviations: $\mathrm{CNI}$, close neighbour interchange; $\mathrm{MCL}$, maximum composite likelihood; ME, minimum-evolution; NJ, neighbour-joining.

The GenBank/EMBL/DDBJ accession numbers for the $16 \mathrm{~S}$ rRNA gene sequences of strains J-G1-2, J-G1-5, J-G2-1 w, J-G2-2 and S-G2-2 ${ }^{\top}$ are D0.913886-D0913890, and those for the partial nifH sequences from the same strains are D0913881-D0913885.

Two supplementary figures and three supplementary tables are available with the online version of this paper.
Only a small fraction of the described species of bacteria and archaea are capable of nitrogen fixation (diazotrophy). Several species of diazotrophs have been the subject of detailed physiological and genetic studies, but many more are known solely from recoverable nitrogen-fixation-specific gene sequences, such as nifH, the gene that encodes the nitrogenase iron protein (Lovell, 2002; Lovell et al., 2000; Zehr \& Capone, 1996). Diversity and ecophysiology of diazotrophs in salt-marsh ecosystems is of particular interest because of the dependence of these systems on diazotrophy for 'new' nitrogen (Hanson, 1983; Patriquin \& McClung, 1978; Whiting \& Morris, 1986) and the great diversity of novel nifH sequences that have been recovered from saltmarsh systems (Brown et al., 2003; Lovell et al., 2000, 2008).

The diazotrophic bacteria described in this paper belong to a new family within the class Gammaproteobacteria. They 
were isolated from roots of the black needle rush Juncus roemerianus and roots of the short growth form of the smooth cordgrass Spartina alterniflora. This new family is of ecological interest because of its ability to fix $\mathrm{N}_{2}$ and its apparent association with the roots of salt-marsh grasses. The decision to classify these strains as representatives of a new family was based on 16S rRNA gene sequence analysis, which provides valuable data on the phylogenetic affiliations of bacteria (Busse et al., 1996; Ludwig et al., 1998; Ludwig \& Schleifer, 1994). Analysis of these sequences showed that the strains formed a clade distinct from known organisms. Due to their motility and ability to fix atmospheric $\mathrm{N}_{2}$, the name Celerinatantimonas diazotrophica gen. nov., sp. nov. is proposed for strains J-G1-2, J-G1-5, J-G2-1w, J-G2-2 and $\mathrm{S}-\mathrm{G} 2-2^{\mathrm{T}}$. Strain S-G2-2 ${ }^{\mathrm{T}}$ is designated the type strain. A new family, Celerinatantimonadaceae fam. nov., is proposed to accommodate $C$. diazotrophica.

All strains were isolated from roots of salt-marsh plants collected from Goat Island in the North Inlet salt marsh near Georgetown, SC, USA ( $\left.33^{\circ} 20^{\prime} \mathrm{N} 79^{\circ} 12^{\prime} \mathrm{W}\right)$ [see Dame \& Kenny (1986) and Morris \& Haskin (1990) for site descriptions]. They were isolated using a root stab inoculation method and combined nitrogen-free semisolid media, both described by Bagwell et al. (1998). Pure cultures were isolated by streak plating on nitrogen-free media and purity was confirmed by microscopic examination and by PCR amplification of $16 \mathrm{~S}$ rRNA gene sequences. Isolates were cultivated on Bacto marine broth (BD Biosciences) supplemented with $15 \mathrm{~g}$ Bacto agar $\mathrm{l}^{-1}$ or in Luria-Bertani broth supplemented with $28 \mathrm{~g} \mathrm{NaCl} \mathrm{l}^{-1}$ (saline LB) to meet the salinity requirement of these organisms. Strain designations were generated from the source plant (J, J. roemerianus; $\mathrm{S}$, short form S. alterniflora), carbon/energy source and $\mathrm{pH}$ of the medium (G, glucose; $\mathrm{S}$, sucrose; $1, \mathrm{pH} 7.0 ; 2, \mathrm{pH} 7.5$ ) and isolate number. These strains were selected based on preliminary $16 \mathrm{~S}$ rRNA gene sequence comparisons that showed $99-100 \%$ similarity among them.

Colony morphology, pigmentation, Gram reaction, motility and cell morphology and arrangement were determined using established methods (Gerhardt et al., 1981). Presence or absence of flagella was determined using the Leifson flagella stain (Clark, 1976). Scanning electron microscopy was used to confirm the cell shape and dimensions (Gerhardt et al., 1981). Optimal growth conditions were determined over ranges of $\mathrm{pH}$, salinity and temperature. Growth responses were determined using triplicate cultures for each growth condition and time interval. The amount of bacterial protein (a surrogate for bacterial mass) was determined using the Rose Bengal dye binding assay (Elliott \& Brewer, 1978). The medium used to determine the salinity growth response was $\mathrm{LB}$, with $\mathrm{NaCl}$ adjusted to achieve the desired salinity. For determination of the optimum $\mathrm{pH}$, saline $\mathrm{LB}(2.8 \% \mathrm{NaCl}$ w/v $)$ was buffered with $10 \mathrm{mM}$ MES for $\mathrm{pH} 3.5-6,10 \mathrm{mM}$ HEPES for $\mathrm{pH}$ 6-8 and $10 \mathrm{mM}$ CAPS for $\mathrm{pH} \mathrm{8-10.} \mathrm{The} \mathrm{medium} \mathrm{used} \mathrm{to}$ determine the temperature growth response contained $\left(1^{-1}\right)$ $10 \mathrm{~g}$ Bacto-tryptone, $5 \mathrm{~g}$ yeast extract, $70 \mathrm{~g} \mathrm{NaCl}$ and $2.38 \mathrm{~g}$
HEPES (pH 6.0). Physiological and biochemical characteristics were determined using API ZYM, 20E and 20NE test strips (bioMérieux), as well as plate and tube tests employing established methods for production of catalase and cytochrome oxidase activities, for reduction of nitrate and for fermentation of glucose. The oxygen requirements for each strain were assessed using Bacto marine broth supplemented with $0.5 \mathrm{~g}$ sodium thioglycolate and $3 \mathrm{~g}$ Bacto agar per litre (Atlas, 1993; Bagwell et al., 1998). Capacity to utilize carbon substrates was tested using Biolog GN2 microplates (Marello \& Bochner, 1989); see Garland \& Mills (1991) for a complete listing of Biolog GN substrates. Positive reactions were scored in triplicate for each strain after incubation and colour reaction development.

The novel strains were Gram-negative, facultatively anaerobic rods. The cells were motile by means of a single polar flagellum. When grown on Bacto marine agar, colonies were tiny, circular, convex and colourless. Ultrathin sectioning and transmission electron microscopy confirmed the Gram reaction (Gerhardt et al., 1981).

API ZYM test strips revealed that all strains produced both acid and alkaline phosphatases, esterase, esterase lipase, leucine arylamidase, $\alpha$-chymotrypsin, naphthol-AS-BI-phosphohydrolase, $\alpha$ - and $\beta$-galactosidase and $\beta$-glucosidase. In addition, strain S-G2-2 ${ }^{\mathrm{T}}$ produced $N$-acetyl- $\beta$-glucosaminidase (chitinase). These activities indicate the capacity to recover phosphate during conditions of phosphorus limitation, as well as the ability to hydrolyse esters and a range of polymeric substrates including both polysaccharides and proteins. All strains were catalase-positive and cytochrome oxidasenegative. Nitrate was not reduced by any strain. All strains performed acid fermentation of glucose.

API 20E test strips confirmed production of $\beta$-galactosidase, fermentation of glucose to acid products and utilization of citrate. All other API 20E tests were negative. The API 20NE test strips confirmed production of $\beta$-galactosidase and $\beta$-glucosidase and assimilation of arabinose, glucose, maltose, mannitol, mannose, $\mathrm{N}$-acetylglucosamine, citrate, gluconate and malate by all strains.

Utilization of a wide variety of carbohydrates and carboxylic acids by the novel strains was consistent with the environment from which they were isolated, as these compounds are abundant in exudates from roots of grasses (e.g. Boyle \& Patriquin, 1981; Hale et al., 1978). Only 15 of the 54 carbohydrates, carboxylic acids and related compounds tested were not utilized by at least one strain. Among the carbohydrates and amino sugars tested, none of the strains utilized $\mathrm{N}$-acetyl-D-galactosamine, i-erythritol, L-fucose or xylitol. All five strains utilized $\mathrm{N}$-acetyl-Dglucosamine, L-arabinose, D-arabitol, cellobiose, D-fructose, D-galactose, gentiobiose, $\alpha$-D-glucose, myo-inositol, lactose, lactulose, D-mannitol, D-mannose, melibiose, methyl $\beta$-Dglucoside, L-rhamnose, sucrose and trehalose. Results for other carbohydrates varied among the five strains (Supplementary Table S1, available in IJSEM Online). Among the carboxylic acids and esters tested, no strain 
utilized D-galacturonic acid lactone, D-glucosaminic acid, $\gamma$-hydroxybutyric acid, $p$-hydroxyphenylacetic acid, $\alpha$ ketobutyric acid, $\alpha$-ketovaleric acid, malonic acid, propionic acid, quinic acid, D-saccharic acid or sebacic acid. All strains utilized cis-aconitic acid, citric acid, Dgalacturonic acid, D-gluconic acid, D-glucuronic acid, $\alpha$ ketoglutaric acid and succinic acid. No two strains utilized exactly the same carbon/energy sources (Supplementary Table S1). The proposed type strain, S-G2-2 ${ }^{\mathrm{T}}$, displayed a substrate utilization profile that was representative of this strain grouping.

Few of the amino acids and betaines tested were utilized by any of the strains. Utilization of amino acids varied among the strains (Supplementary Table S1). The only amino acid used by all five strains was proline, a common osmolyte which may be of particular importance in an environment subject to periodically high salinity. None of the organophosphorus compounds or primary amines tested were utilized, nor were inosine, uridine, thymidine, 2,3-butanediol or $\alpha$-cyclodextrin. Glycerol, bromosuccinic acid, dextrin and glycogen were used by all five strains. Utilization of other compounds varied among the strains (Supplementary Table S1).

Fatty acid methyl ester analysis (MIDI, Inc.) was performed on all strains. Analysis of fatty acid profiles did not correlate with any known bacteria in their database (not shown). The predominant fatty acids present, accounting for over $85 \%$ of total fatty acid content, were summed feature 2 [comprising $\mathrm{C}_{12: 0}$ aldehyde and/or unknown fatty acid 10.9525 (MIDI designation) and/or iso- $\mathrm{C}_{16: 1} \mathrm{I} / \mathrm{C}_{14: 0}$ $3-\mathrm{OH}]$, summed feature $3\left(\mathrm{C}_{16: 1} \omega 7 c / \mathrm{C}_{16: 1} \omega 6 c\right), \mathrm{C}_{16: 0}$, $\mathrm{C}_{17: 0}$ cyclo and summed feature $8\left(\mathrm{C}_{18: 1} \omega 7 c / \mathrm{C}_{18: 1} \omega 6 c\right)$. Minor fatty acid cellular components can be found in Supplementary Table S2.

DNA from each strain was extracted and purified using the Wizard genomic purification kit and DNA cleanup system (Promega), respectively. The bacteria-specific primers $27 \mathrm{~F}$ (forward) and 1492R (reverse) (Lane, 1991) were used to amplify nearly full-length $16 \mathrm{~S}$ rRNA genes. The thermal cycling program was: $94{ }^{\circ} \mathrm{C}$ for $3 \mathrm{~min}, 5$ cycles of $95{ }^{\circ} \mathrm{C}$ for $1 \mathrm{~min}, 40{ }^{\circ} \mathrm{C}$ for $1 \mathrm{~min}$ and $72{ }^{\circ} \mathrm{C}$ for $90 \mathrm{~s} ; 30$ cycles of $95{ }^{\circ} \mathrm{C}$ for $1 \mathrm{~min}, 43{ }^{\circ} \mathrm{C}$ for $1 \mathrm{~min}$ and $72{ }^{\circ} \mathrm{C}$ for $90 \mathrm{~s}$; and a final extension at $72{ }^{\circ} \mathrm{C}$ for $5 \mathrm{~min}$. Sequence determination followed the protocol described by Lovell et al. (2008) but employed primers 519F, 1099F, 529R, 907R and 1240R (Zhou et al., 1995). The thermal cycling program for sequencing was 34 cycles of $96{ }^{\circ} \mathrm{C}$ for $10 \mathrm{~s}, 50{ }^{\circ} \mathrm{C}$ for $5 \mathrm{~s}$ and $60{ }^{\circ} \mathrm{C}$ for $4 \mathrm{~min}$, and sequences were determined using an ABI 3100 DNA analyser.

The NCBI GenBank BLAST utility (Altschul et al., 1997; Benson et al., 1998) was used to identify 16S rRNA gene sequences similar to those of the strains examined. Based on BLAST analysis, the type species of each genus in the Alteromonadales was then used for phylogenetic analysis. Nucleotide sequences were aligned using CLUSTAL_X (Chenna et al., 2003; Thompson et al., 1997) and imported into MEGA version 4.0 (Tamura et al., 2007). Phylogenetic trees were constructed in MEGA using complete deletion of gaps and missing data. The neighbour-joining (NJ) phylogeny was reconstructed with the Jukes-Cantor model for nucleotide substitution. This tree was used as the base for the consensus tree. The minimum-evolution (ME) tree also used the Jukes-Cantor substitution model and a closeneighbour-interchange (CNI) value of 2 . The maximumcomposite-likelihood (MCL) tree was created with the MCL model and CNI of 2. Bootstrap values from 1000 bootstrap resamplings $(\geqslant 75 \%)$ (Felsenstein, 1985) for NJ, ME and MCL were then applied to the consensus tree (Fig. 1).

The 16S rRNA gene sequences of the five novel strains differed from each other by no more than $0.4 \%$. Comparison of the nearly full-length $16 \mathrm{~S}$ rRNA gene sequences from the five salt-marsh strains to those in the NCBI database supported placement of these strains in the Gammaproteobacteria, with affinity to the Alteromonadales. The highest nucleotide sequence similarity to a member of a formally described taxon (Idiomarina seosinensis PR58-8) was $91 \%$. Phylogenetic analysis (Fig. 1) showed that the novel strains represent a monophyletic lineage distinct from other members of the Gammaproteobacteria. This placement was strongly supported by bootstrap analysis for all three phylogenetic reconstruction methods. The inability of the salt-marsh strains to reduce nitrate or produce cytochrome oxidase differentiates them from most of these other members of the Alteromonadales (Bowman \& McMeekin, 2005). They were also differentiated from Idiomarina seosinensis by their ability to utilize sucrose and D-mannose and their ability to reduce nitrate.

Partial nifH sequences were amplified following the methods of Lovell et al. (2000) using the thermal cycling program described by Piceno et al. (1999). The nifH amplicons were ligated into pGEM-T (Promega) and the recombinant plasmids were used to transform competent cells of Escherichia coli JM109 (Promega). Recombinant clones were selected, recombinant plasmids analysed and nucleotide sequences determined following the methods of Lovell et al. (2000, 2008).

Sequences of the nifH genes from the novel strains were compared to sequences from known diazotrophs. The NJ phylogeny was reconstructed in MEGA using complete deletion of gaps and missing data and Kimura's twoparameter model with a gamma correction of 2. The ME tree was used as the base tree and was reconstructed using Kimura's two-parameter model and gamma correction of 2 with complete deletion of gaps and missing data and CNI of 2. The MCL tree was reconstructed using complete deletion, the MCL model and CNI of 2. Nucleotide sequences were aligned using CLUSTAL_X, imported into MEGA and NJ, ME and MCL phylogenies were reconstructed as before. Bootstrap values were applied as described for the 16S rRNA gene tree.

Analysis of nifH has proven to be a reliable tool for phylogenetic reconstructions (e.g. Lovell, 2002; Zehr et al., 


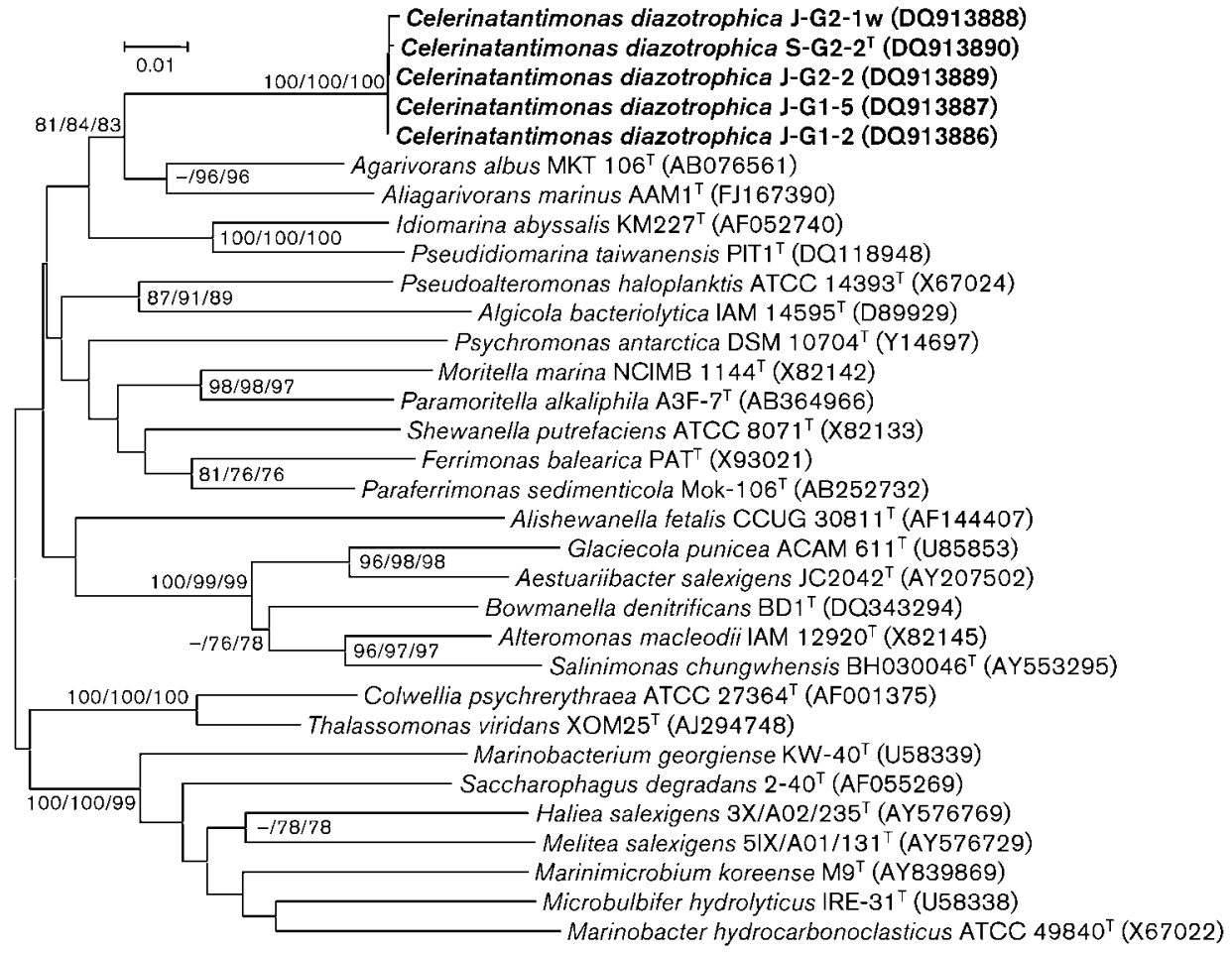

Fig. 1. Phylogenetic analysis showing relationships of full-length $16 \mathrm{~S}$ rRNA gene sequences from strains J-G1-2, J-G1-5, J-G2-1w, J-G2-2 and S-G2-2 ${ }^{\top}$ and the type species of each genus in the Alteromonadales, identified as the order of the Gammaproteobacteria that was most closely related to the strains based on BLAST analysis. Bootstrap analysis employed 1000 replicates and bootstrap values below $75 \%$ are not shown. The bootstrap values shown at each node reflect analyses from three phylogenetic reconstruction methods listed in the order NJ/ME/MCL;,$-<75 \%$. Bar, $1 \%$ estimated sequence divergence.

2003). Sequences from the novel salt-marsh strains were allied with those from authentic gammaproteobacteria (Supplementary Fig. S1). Analysis of nifH also showed that the salt-marsh sequences formed a monophyletic grouping well separated from sequences from formally described diazotrophs. Unfortunately, no nifH sequences from any other organisms in the Alteromonadales are available at present. None of the currently described taxa are known to be diazotrophic, but it is not clear that all have been tested for this capability. Sequences from the novel strains were very similar to each other, showing $96.7-100 \%$ identity for the nucleotide sequences and $97.5-100 \%$ identity for translated amino acid sequences. The levels of similarity between the nifH sequences of the novel strains and those from their nearest neighbours among known diazotrophs were too low to indicate any close relationship. The nifH sequences of the novel salt-marsh strains were more similar to nifH sequences recovered from uncharacterized environmental strains than to those from any formally described taxa. In particular, sequences from nitrogen-fixing strains recovered from marine cyanobacterial mats were affiliated with those of the novel strains (Supplementary Fig. S1) (Steppe et al., 1996), though nucleotide sequence similarities were $92-95 \%$. These mat organisms were also derived from environments subject to substantial variability in salinity, $\mathrm{pH}$ and temperature.

The $\mathrm{G}+\mathrm{C}$ content of each strain was determined in triplicate using the HPLC method of Mesbah et al. (1989); see also Mesbah \& Whitman (1989). The nucleoside products of acid hydrolysis of purified DNA (Mesbah et al., 1989) were resolved using a Hewlett Packard series 1100 HPLC equipped with a C18 reversed-phase column $(250 \times 4.6 \mathrm{~mm}, 5 \mu \mathrm{m}$ particle size; Alltech). Amounts of nucleosides were determined from standard curves of pure compounds. The $\mathrm{G}+\mathrm{C}$ content of the five novel strains ranged from 41.5 to $44.4 \mathrm{~mol} \%$ (mean $42.6 \mathrm{~mol} \%$ ) and the $\mathrm{G}+\mathrm{C}$ content of the proposed type strain $\left(\mathrm{S}-\mathrm{G} 2-2^{\mathrm{T}}\right)$ was $41.5 \pm 0.3 \mathrm{~mol} \%$.

Whole-genome relatedness was assessed to examine whether the strains were members of the same species. DNA-DNA relatedness measurements were made following the fluorimetric method described by Gonzalez \& SaizJimenez (2005). Genomic DNA was extracted and purified as described above for DNA sequencing, quantified using a NanoDrop 1000 spectrophotometer (Thermo Scientific) and normalized to $25 \mathrm{ng} \mu \mathrm{l}^{-1}$ in distilled water. All possible pairwise combinations were replicated $(n=4)$ in a 
96-well microtitre plate format in $50 \mu$ (final volume) $0.1 \times$ SSC $(\mathrm{pH} 8.0)$. Denatured genome pairings were first incubated at the theoretical optimum renaturation temperature $\left(T_{\text {or }} 68.6{ }^{\circ} \mathrm{C}\right)$ and cooled stepwise to $25{ }^{\circ} \mathrm{C}$ prior to melting-curve analysis $\left(+2{ }^{\circ} \mathrm{C} \mathrm{s}^{-1} ; 6 \mathrm{~s}\right.$ dwell time) using SYBR Green I (Invitrogen) and the MyiQ Real-Time PCR detection system (Bio-Rad). Regression analysis was used to determine the thermal denaturation temperature $\left(T_{\mathrm{m}}\right)$ of the hybrid-genome pairs and homologous genomes. Applying a $\Delta T_{\mathrm{m}}$ of $5{ }^{\circ} \mathrm{C}$ as the species level cut-off (Gonzalez \& Saiz-Jimenez, 2005; Kumar \& Goodfellow, 2008), these cultures are clearly members of the same species. All hybrid genome pairings yielded a $\Delta T_{\mathrm{m}}<1{ }^{\circ} \mathrm{C}$ except for the combination S-G2-2 ${ }^{\mathrm{T}}: \mathrm{J}-\mathrm{G} 1-5$, which had a $\Delta T_{\mathrm{m}}$ of $1.2^{\circ} \mathrm{C}$.

Polar lipid and respiratory quinone analyses were carried out by the Identification Services of the Deutsche Sammlung von Mikroorganismen und Zellkulturen GmbH (DSMZ), Braunschweig, Germany, and Dr B. J. Tindall (DSMZ). Polar lipid analysis revealed the presence of diphosphatidylglycerol, phosphatidylglycerol, phosphatidylethanolamine, phosphatidylmonomethylethanolamine and aminophospholipid as well as phospholipids and unidentified aminolipids (Supplementary Fig. S2). Respiratory quinone analysis detected menaquinone MK$8(100 \%)$ and ubiquinones Q-8 (93\%), Q-9 (5\%) and Q-7 (2\%).

The decision that the novel strains should be assigned to a new family within the Alteromonadales was consistent with previous work within the class Gammaproteobacteria. Members of the Alteromonadales are marine, Gramnegative, rod-shaped bacteria with a single polar flagellum, with a $\mathrm{G}+\mathrm{C}$ content of $36-54 \mathrm{~mol} \%$. Most are catalasepositive and require sodium for growth. Ubiquinone Q-8 is the major coenzyme Q (Bowman \& McMeekin, 2005). The novel strains fit these parameters. Designation of a new family was based primarily on 16S rRNA gene sequence analysis. Golyshin et al. (2002) proposed the new family Oleiphilaceae based upon divergence from the nearest taxon amounting to a $16 \mathrm{~S}$ rRNA gene sequence similarity of $91 \%$. Operational genetic unit analysis conducted by Ivanova et al. (2004) revealed that genera within the Pseudoalteromonadaceae were delimited by sequence similarities $\leqslant 93 \%$. Sequence similarity scores of $83-85$ and $90 \%$ to the nearest formally described taxa supported the establishment of the Pseudoalteromonadaceae as a new family (Ivanova et al., 2004). The novel salt-marsh strains are divergent from their nearest neighbour within these parameters and we therefore propose a new family to accommodate them. Furthermore, they are easily distinguished from members of other families within the Alteromonadales in that they are oxidase-negative and able to grow at $42{ }^{\circ} \mathrm{C}$.

A particularly important feature of the novel strains is their ability to fix atmospheric nitrogen. To demonstrate $\mathrm{N}_{2}$ fixation capability, the strains were grown in triplicate on/ in a mineral salts medium containing $\left(1^{-1}\right) 24 \mathrm{~g} \mathrm{NaCl}$, $0.5 \mathrm{~g} \mathrm{MgSO}_{4}, 0.01 \mathrm{~g} \mathrm{CaCl}_{2}, 0.01 \mathrm{~g} \mathrm{Na}_{2} \mathrm{MoO}_{4}, 6.06 \mathrm{~g}$ Trizma base, $15 \mathrm{~g}$ Difco noble agar (plates only) (pH 7.5). After autoclaving, the basal medium was supplemented with filter-sterilized glucose $(60 \mathrm{mM}$ final concentration), $\mathrm{FeCl}_{3}(0.05 \mathrm{mM})$ and $\mathrm{K}_{2} \mathrm{HPO}_{4}(3 \mathrm{mM})$ (Bagwell et al., 1998). Forty millilitre serum bottles containing $10 \mathrm{ml}$ combined nitrogen-free medium under $30 \mathrm{ml} \mathrm{N}_{2}$ headspace were inoculated and the gas phase was brought to $10 \%$ acetylene. Ethylene was detected using a Shimadzu GC-8A gas chromatograph equipped with a Porapak T80/100 stainless steel column with dimensions $6^{\prime} \times 1 / 8^{\prime \prime} \times 0.085^{\prime \prime} \quad(1.83 \mathrm{~m} \times 3.2 \mathrm{~mm} \times 2.2 \mathrm{~mm}) \quad$ (Alltech Associates Inc.) and a Hewlett Packard 3390A integrator. All specific activity measurements were performed in triplicate. All of the salt-marsh strains reduced acetylene to ethylene (Supplementary Table S3), a commonly used assay for nitrogenase activity. Nitrogenase activity was maximal for these strains at $2.7 \% \mathrm{NaCl}$ and $\mathrm{pH}$ 7.5. Additional evidence for $\mathrm{N}_{2}$ fixation included growth in combined nitrogen-free media and recovery of partial sequences of the gene encoding the nitrogenase iron protein, nifH. The capacity to fix $\mathrm{N}_{2}$ is clearly advantageous in the nitrogen-limited salt-marsh environment and is consistent with the finding of most nitrogen-fixation activity on and around the roots of estuarine plants, including J. roemerianus and S. alterniflora (e.g. Gandy \& Yoch, 1988; Whiting et al., 1986).

Based on a high degree of $16 \mathrm{~S}$ rRNA sequence divergence, as well as differences in $\mathrm{G}+\mathrm{C}$ content and a number of physiological characters, from other known members of the Alteromonadales, we propose a new family in the Alteromonadales, the Celerinatantimonadaceae fam. nov. This family currently includes one genus, Celerinatantimonas gen. nov., represented by the type and only species, Celerinatantimonas diazotrophica gen. nov., sp. nov.

\section{Description of Celerinatantimonas gen. nov.}

Celerinatantimonas (Ce.le.ri.na.tan'ti.mo'nas. L. adj. celer swift; L. adj. natans swimming; Gr. fem. n. monas unit; N.L. fem. $\mathrm{n}$. Celerinatantimonas the swift swimming unit).

Cells are Gram-negative, motile, polarly monotrichous, facultatively anaerobic, thick rods. Require mesophilic conditions and seawater salts or $\mathrm{NaCl}$ for growth. Oxidasenegative and catalase-positive. The $\mathrm{G}+\mathrm{C}$ content of the DNA isolated from five strains of the single species is 41.5$44.4 \mathrm{~mol} \%$ (Table 1). The genus is a member of the Gammaproteobacteria. The type and only species is Celerinatantimonas diazotrophica.

\section{Description of Celerinatantimonas diazotrophica sp. nov.}

Celerinatantimonas diazotrophica [di.a'zo.tro'phi.ca. Gr. adv. dis twice, doubly; N.L. n. azotum nitrogen; N.L. pref. diazo- pertaining to dinitrogen; N.L. fem. adj. trophica 


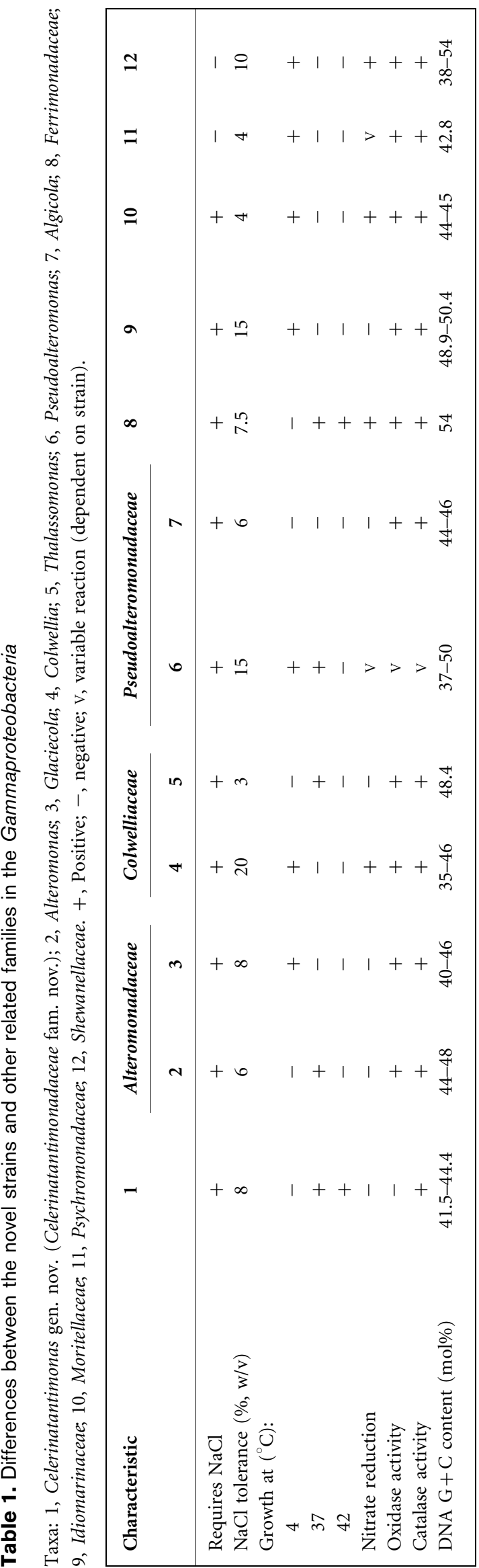

(from Gr. fem. adj. trophikê) nursing, tending; N.L. fem. adj. diazotrophica growing on dinitrogen].

Displays the following properties in addition to those described for the genus. Grows at $17-49{ }^{\circ} \mathrm{C}$, with optimal growth at $31{ }^{\circ} \mathrm{C}$. Growth occurs at $\mathrm{NaCl}$ concentrations of $2.5-8.0 \%$, with optimal growth at 7.0-7.5\%. Growth occurs at $\mathrm{pH} 3.5-8.0$, with optimal growth at $\mathrm{pH}$ 6.0. Does not produce the extracellular enzymes amylase, gelatinase, casein protease or lipase. Nitrate is not reduced. Known strains are positive for the production of acid and alkaline phosphatases, esterase, esterase lipase, leucine arylamidase, $\alpha$-chymotrypsin, naphthol-AS-BI-phosphohydrolase, $\alpha$ and $\beta$-galactosidase and $\beta$-glucosidase. The type strain produces $N$-acetyl- $\beta$-glucosaminidase (chitinase), but the other known strains do not. Negative for $\alpha$-fucosidase, $\alpha$-glucosidase, $\alpha$-mannosidase and $\beta$-glucuronidase. Strain J-G1-2 produces weakly positive reactions for lipase (C14), cystine arylamidase and trypsin with API ZYM test strips; all other strains give negative results. Strain J-G1-5 produces a weakly positive reaction with valine arylamidase with API ZYM test strips; all other strains are positive. Utilizes $N$-acetyl-D-glucosamine, L-arabinose, D-arabitol, cellobiose, D-fructose, D-galactose, gentiobiose, $\alpha$-D-glucose, myo-inositol, lactose, lactulose, D-mannitol, D-mannose, melibiose, methyl $\beta$-D-glucoside, L-rhamnose, sucrose, trehalose, glycerol, cis-aconitic acid, citric acid, D-galacturonic acid, D-gluconic acid, D-glucuronic acid, $\alpha$-ketoglutaric acid, succinic acid, bromosuccinic acid, dextrin, glycogen, L-proline and malate. Does not utilize $N$-acetyl-Dgalactosamine, i-erythritol, L-fucose, xylitol, phenylethylamine, putrescine, 2-aminoethanol, 2,3-butanediol, DL- $\alpha$ glycerol phosphate, $\alpha$-D-glucose 1-phosphate, D-glucose 6-phosphate, D-galacturonic acid lactone, D-glucosaminic acid, $\gamma$-hydroxybutyric acid, $p$-hydroxyphenylacetic acid, $\alpha$-ketobutyric acid, $\alpha$-ketovaleric acid, malonic acid, propionic acid, quinic acid, D-saccharic acid, sebacic acid, L-alaninamide, $\alpha$-cyclodextrin, D- or L-alanine, L-alanyl glycine, L-aspartic acid, glycyl L-aspartic acid, glycyl L-glutamic acid, L-histidine, hydroxy-L-proline, L-leucine, L-ornithine, L-phenylalanine, L-pyroglutamic acid, D- or Lserine, L-threonine, DL-carnitine, urocanic acid, inosine, uridine or thymidine. Variable results are seen for utilization of adonitol, maltose, D-psicose, raffinose, D-sorbitol, turanose, pyruvic acid methyl ester, succinic acid monomethyl ester, acetic acid, formic acid, $\alpha$-hydroxybutyric acid, $\beta$ hydroxybutyric acid, itaconic acid, DL-lactic acid, succinamic acid, glucuronamide, Tweens 40 and 80, L-asparagine, L-glutamic acid and $\gamma$-aminobutyric acid. Of these carbon sources, the type strain utilizes maltose, D-psicose, succinic acid monomethyl ester, acetic acid, DL-lactic acid, glucuronamide and L-glutamic acid. The type strain also produces $\alpha$ - and $\beta$-galactosidase, $\beta$-glucosidase and acid and alkaline phosphatases.

The type strain, S-G2-2 $2^{\mathrm{T}}$ (=ATCC BAA- $1368^{\mathrm{T}}=\mathrm{DSM}$ $18577^{\mathrm{T}}$ ), was isolated from a Spartina alterniflora root sample from the North Inlet salt marsh near Georgetown, SC, USA. Other strains of the species, isolated from similar 
sources, are J-G2-2 (=DSM 18573), J-G1-1w (=DSM 18574), J-G1-5 (=DSM 18575) and J-G1-2 (=ATCC BAA$1369=$ DSM 18576).

\section{Description of Celerinatantimonadaceae fam. nov.}

Celerinatantimonadaceae (Ce.le.ri.na.tan'ti.mo.na.da'ce.ae. N.L. fem. n. Celerinatantimonas a bacterial genus; L. suff. -aceae ending to denote a family; N.L. fem. pl. n. Celerinatantimonadaceae the Celerinatantimonas family).

The description is as for the genus Celerinatantimonas. The type and only genus is Celerinatantimonas.

\section{Acknowledgements}

This research was supported by NSF award MCB-0237854 to C. R. L. We acknowledge Mike Friez for assistance with DNA sequencing, Ward Briggs for assistance with Latin and Amy Ashburne-Lucas for her assistance in isolating these organisms.

\section{References}

Altschul, S. F., Madden, T. L., Schäffer, A. A., Zhang, J., Zhang, Z., Miller, W. \& Lipman, D. J. (1997). Gapped BLAST and PSI-BLAST: a new generation of protein database search programs. Nucleic Acids Res 25, 3389-3402.

Atlas, R. M. (1993). Handbook of Microbiological Media. Boca Raton, FL: CRC Press.

Bagwell, C. E., Piceno, Y. M., Ashburne-Lucas, A. \& Lovell, C. R. (1998). Physiological diversity of the rhizosphere diazotroph assemblages of selected salt marsh grasses. Appl Environ Microbiol 64, 4276-4282.

Benson, D. A., Boguski, M. S., Lipman, D. J., Ostell, J. \& Ouellette, B. F. (1998). GenBank. Nucleic Acids Res 26, 1-7.

Bowman, J. P. \& McMeekin, T. A. (2005). Order X. Alteromonadales ord. nov. In Bergey's Manual of Systematic Bacteriology, 2nd edn, vol. 2B, p. 443. Edited by D. J. Brenner, N. R. Krieg, J. T. Staley \& G. M. Garrity. New York: Springer.

Boyle, C. D. \& Patriquin, D. G. (1981). Carbon metabolism of Spartina alterniflora Loisel in relation to that of associated nitrogen-fixing bacteria. New Phytol 89, 275-288.

Brown, M. M., Friez, M. J. \& Lovell, C. R. (2003). Expression of nifH genes by diazotrophic bacteria in the rhizosphere of short form Spartina alterniflora. FEMS Microbiol Ecol 43, 411-417.

Busse, H.-J., Denner, E. B. M. \& Lubitz, W. (1996). Classification and identification of bacteria: current approaches to an old problem. Overview of methods used in bacterial systematics. J Biotechnol 47, 338.

Chenna, R., Sugawara, H., Koike, T., Lopez, R., Gibson, T. J., Higgins, D. G. \& Thompson, J. D. (2003). Multiple sequence alignment with the CLUSTAL series of programs. Nucleic Acids Res 31, 3497-3500. .

Clark, W. A. (1976). A simplified Leifson flagella stain. J Clin Microbiol 3, 632-634.

Dame, R. F. \& Kenny, P. D. (1986). Variability of Spartina alterniflora primary production in the euhaline North Inlet Estuary. Mar Ecol Prog Ser 32, 71-80.

Elliott, J. I. \& Brewer, J. M. (1978). The inactivation of yeast enolase by 2,3-butanedione. Arch Biochem Biophys 190, 351-357.
Felsenstein, J. (1985). Confidence limits on phylogenies: an approach using the bootstrap. Evolution 39, 783-791.

Gandy, E. L. \& Yoch, D. C. (1988). Relationship between nitrogenfixing sulfate reducers and fermenters in salt marsh sediments and roots of Spartina alterniflora. Appl Environ Microbiol 54, 2031-2036.

Garland, J. L. \& Mills, A. L. (1991). Classification and characterization of heterotrophic microbial communities on the basis of patterns of community-level sole-carbon-source utilization. Appl Environ Microbiol 57, 2351-2359.

Gerhardt, P., Murray, R. G. E., Costilow, T. N., Nester, E. W., Wood, W. A., Krieg, N. R. \& Phillips, G. B. (1981). Manual of Methods for General Bacteriology. Washington, DC: American Society for Microbiology.

Golyshin, P. N., Chernikova, T. N., Abraham, W. R., Lünsdorf, H., Timmis, K. N. \& Yakimov, M. M. (2002). Oleiphilaceae fam. nov., to include Oleiphilus messinensis gen. nov., sp. nov., a novel marine bacterium that obligately utilizes hydrocarbons. Int $J$ Syst Evol Microbiol 52, 901-911.

Gonzalez, J. M. \& Saiz-Jimenez, C. (2005). A simple fluorimetric method for the estimation of DNA-DNA relatedness between closely related microorganisms by thermal denaturation temperatures. Extremophiles 9, 75-79.

Hale, M. G., Moore, L. D. \& Griffin, G. J. (1978). Root exudates and exudation. In Interactions between Non-pathogenic Soil Microorganisms and Plants, pp. 163-203. Edited by Y. R. Dommergues \& S. V. Krupa. New York: Elsevier.

Hanson, R. B. (1983). Nitrogen fixation activity (acetylene reduction) in the rhizosphere of salt marsh angiosperms, Georgia, USA. Bot Mar 26, 49-60.

Ivanova, E. P., Flavier, S. \& Christen, R. (2004). Phylogenetic relationships among marine Alteromonas-like proteobacteria: emended description of the family Alteromonadaceae and proposal of Pseudoalteromonadaceae fam. nov., Colwelliaceae fam. nov., Shewanellaceae fam. nov., Moritellaceae fam. nov., Ferrimonadaceae fam. nov., Idiomarinaceae fam. nov. and Psychromonadaceae fam. nov. Int J Syst Evol Microbiol 54, 1773-1788.

Kumar, Y. \& Goodfellow, M. (2008). Five new members of the Streptomyces violaceusniger $16 \mathrm{~S}$ rRNA gene clade: Streptomyces castelarensis sp. nov., comb. nov., Streptomyces himastatinicus sp. nov., Streptomyces mordarskii sp. nov., Streptomyces rapamycinicus sp. nov. and Streptomyces ruanii sp. nov. Int J Syst Evol Microbiol 58, 1369-1378.

Lane, D. J. (1991). 16S/23S rRNA sequencing. In Nucleic Acid Techniques in Bacterial Systematics, pp. 115-175. Edited by E. Stackebrandt \& M. Goodfellow. Chichester: Wiley.

Lovell, C. R. (2002). Plant-microbe interactions in the marine environment. In The Encyclopedia of Environmental Microbiology, vol. 5, pp. 2539-3544. Edited by G. Bitton. New York: Wiley.

Lovell, C. R., Piceno, Y. M., Quattro, J. M. \& Bagwell, C. E. (2000). Molecular analysis of diazotroph diversity in the rhizosphere of the smooth cordgrass, Spartina alterniflora. Appl Environ Microbiol 66, 3814-3822.

Lovell, C. R., Decker, P. V., Bagwell, C. E., Thompson, S. \& Matsui, G. Y. (2008). Analysis of a diverse assemblage of diazotrophic bacteria from Spartina alterniflora using DGGE and clone library screening. J Microbiol Methods 73, 160-171.

Ludwig, W. \& Schleifer, K. H. (1994). Bacterial phylogeny based on $16 \mathrm{~S}$ and 23S rRNA sequence analysis. FEMS Microbiol Rev 15, 155173.

Ludwig, W., Strunk, O., Klugbauer, S., Klugbauer, N., Weizenegger, M., Neumaier, J., Bachleitner, M. \& Schleifer, K. H. (1998). Bacterial phylogeny based on comparative sequence analysis. Electrophoresis 19, 554-568. 
Marello, T. A. \& Bochner, B. R. (1989). BIOLOG References Manual: Metabolic Reactions of Gram-negative Species. Haywood, CA: Biolog and Science Tech Publishers.

Mesbah, M. \& Whitman, W. B. (1989). Measurement of deoxyguanosine/thymidine ratios in complex mixtures by high-performance liquid chromatography for determination of the mole percentage guanine + cytosine of DNA. J Chromatogr A 479, 297-306.

Mesbah, M., Premachandran, U. \& Whitman, W. B. (1989). Precise measurement of the $\mathrm{G}+\mathrm{C}$ content of deoxyribonucleic acid by highperformance liquid chromatography. Int J Syst Bacteriol 39, 159-167.

Morris, J. T. \& Haskin, B. (1990). A 5-year record of aerial primary production and stand characteristics of Spartina alterniflora. Ecology 71, 2209-2217.

Patriquin, D. G. \& McClung, C. R. (1978). Nitrogen accretion, and nature and possible significance of $\mathrm{N}_{2}$ fixation (acetylene reduction) in a Nova Scotian Spartina alterniflora stand. Mar Biol 47, 227242.

Piceno, Y. M., Noble, P. A. \& Lovell, C. R. (1999). Spatial and temporal assessment of diazotroph assemblage composition in vegetated salt marsh sediments using denaturing gradient gel electrophoresis analysis. Microb Ecol 38, 157-167.

Steppe, T. F., Olson, J. B., Paerl, H. W., Litaker, R. W. \& Belnap, J. (1996). Consortial $\mathrm{N}_{2}$ fixation: a strategy for meeting nitrogen requirements of marine and terrestrial cyanobacterial mats. FEMS Microbiol Ecol 21, 149-156.
Tamura, K., Dudley, J., Nei, M. \& Kumar, S. (2007). MEGA4: molecular evolutionary genetics analysis (MEGA) software version 4.0. Mol Biol Evol 24, 1596-1599.

Thompson, J. D., Gibson, T. J., Plewniak, F., Jeanmougin, F. \& Higgins, D. G. (1997). The CLUSTAL_X windows interface: flexible strategies for multiple sequence alignment aided by quality analysis tools. Nucleic Acids Res 25, 4876-4882.

Whiting, G. J. \& Morris, J. T. (1986). Nitrogen fixation $\left(\mathrm{C}_{2} \mathrm{H}_{2}\right.$ reduction) in a salt marsh: its relationship to temperature and an evaluation of an in situ chamber technique. Soil Biol Biochem 18, 515521.

Whiting, G. J., Gandy, E. L. \& Yoch, D. C. (1986). Tight coupling of root-associated nitrogen fixation and plant photosynthesis in the salt marsh grass Spartina alterniflora and carbon dioxide enhancement of nitrogenase activity. Appl Environ Microbiol 52, 108-113.

Zehr, J. P. \& Capone, D. G. (1996). Problems and promises of assaying the genetic potential for nitrogen fixation in the marine environment. Microb Ecol 32, 263-281.

Zehr, J. P., Jenkins, B. D., Short, S. M. \& Steward, G. F. (2003). Nitrogenase gene diversity and microbial community structure: a cross-system comparison. Environ Microbiol 5, 539-554.

Zhou, J.-Z., Fries, M. R., Chee-Sanford, J. C. \& Tiedje, J. M. (1995). Phylogenetic analyses of a new group of denitrifiers capable of anaerobic growth of toluene and description of Azoarcus tolulyticus sp. nov. Int J Syst Bacteriol 45, 500-506. 